\title{
AVALIAÇÃO DO USO DE BIOMASSA BACTERIANA IMOBILIZADA NA BIOSSORÇÃO DE TERRAS-RARAS LEVES E MÉDIAS
}

\author{
N. V. COIMBRA, M. NASCIMENTO, E. C. GIESE* \\ Centro de Tecnologia Mineral (CETEM), Rio de Janeiro, Brasil \\ egiese@cetem.gov.br
}

Submetido 18/10/2017 - Aceito 28/11/2017

DOI: $10.15628 /$ holos.2017.6445

\begin{abstract}
RESUMO
A busca por fontes alternativas de recuperação e separação dos elementos puros de terras-raras (TRs) é vista como uma ação prioritária e estratégica por diversos países demandantes desses elementos. Em alternativa aos processos clássicos de extração de TRs, o processo de biossorção vem sendo avaliado, em uma combinação da biotecnologia e metalurgia extrativa. Sendo assim, o presente trabalho buscou avaliar a capacidade da biomassa imobilizada da bactéria Bacillussubtilis na biossorção de lantânio (TR leve) e samário (TR médio), visando seu uso na separação desses elementos. As maiores porcentagens de biossorção de lantânio (La) e samário ( $\mathrm{Sm}$ ) em sistemas mono-elementares corresponderam à $94,4 \%$ e $94,9 \%$, respectivamente, a partir de concentrações iguais $\left(C_{i}\right)$ à
\end{abstract}

$15 \mathrm{mg} / \mathrm{L}$. Em soluções com $\mathrm{C}_{\mathrm{i}}=100 \mathrm{mg} / \mathrm{L}, 89,3 \%$ de La e 91,9\% de Sm foram biossorvidos. O mesmo comportamento pode ser observado para a solução bielementar La+Sm, onde $79,9 \%$ de La e $88,8 \%$ de Sm foram biossorvidos em soluções com $C_{i}=15 \mathrm{mg} / \mathrm{L}$, e, $69,4 \%$ de La e $83,4 \%$ de Sm foram biossorvidos em $C_{i}$ $=100 \mathrm{mg} / \mathrm{L}$. A aplicação dos dados obtidos aos modelos de adsorção de Langmuir e Freundlich demonstrou que as isotermas de adsorção obtidas para La e Sm em ambos os sistemas avaliados foram satisfatórias para ambos os modelos, sugerindo a ocorrência da biossorção em monocamada assim como condições heterogêneas na superfície, onde ambas condições podem co-existir sob as condições experimentais testadas.

PALAVRAS-CHAVE: Bacillussubtilis, imobilização celular, alginato de cálcio, biossorção, terras-raras

\section{EVALUATION OF THE USE OF BACTERIAL IMMOBILIZED BIOMASS IN LIGHT AND MEDIUM RARE-EARTH ELEMENTS BIOSORPTION}

\begin{abstract}
The search for alternative sources of recovery and separation of pure rare earth elements (REE) is a priority and strategic action by several countries demanding these elements. As an alternative to classical processes of extraction of REE, the biosorption process has been evaluated in a combination between biotechnology and extractive metallurgy. Therefore, the present work aimed to evaluate the capacity of immobilized biomass of Bacillus subtilis to the biosorption of lanthanum (light REE) and samarium (medium REE), aiming its use in the separation of these elements. The highest percentages of lanthanum (La) and samarium (Sm) biosorption in single-element systems corresponded to $94.4 \%$ and $94.9 \%$, respectively, from an initial concentration $\left({ }_{i} \mathrm{C}\right)$ of
\end{abstract}

$15 \mathrm{mg} / \mathrm{L}$. In solutions with ${ }_{\mathrm{C}} \mathrm{C}=100 \mathrm{mg} / \mathrm{L}, 89.3 \%$ of $\mathrm{La}$ and $91.9 \%$ of $\mathrm{Sm}$ were biosorbed. The same behavior can be observed for the bi-elemental solution $\mathrm{La}+\mathrm{Sm}$, where $79.9 \%$ of $\mathrm{La}$ and $88.8 \%$ of $\mathrm{Sm}$ were biosorbed in solutions of ${ }_{i} \mathrm{C}=15 \mathrm{mg} / \mathrm{L}$, and $69.4 \%$ of $\mathrm{La}$ and $83.4 \%$ of $\mathrm{Sm}$ were biosorbed in ${ }_{\mathrm{i}} \mathrm{C}=100 \mathrm{mg} / \mathrm{L}$. The application of the data obtained to the adsorption models of Langmuir and Freundlich showed that the adsorption isotherms obtained for La and Sm in both systems were satisfactory for both models, suggesting the occurrence of monolayer biosorption as well as heterogeneous surface conditions, where both conditions can co-exist under the experimental conditions tested.

KEYWORDS: Bacillus subtilis, cell immobilization, calcium alginate, biosorption, rare-earth elements 


\section{INTRODUÇÃO}

O alto custo dos processos de separação dos elementos de terras raras (TRs) visando à obtenção de compostos mais puros acaba por elevar o valor de mercado destes elementos, pois, em geral, estes processos envolvem várias etapas de extração por solventes e/ou o uso de resinas de troca-iônica e tais tecnologias poucos países as dominam (Silva Júnior \& Campos, 2016, Vera, 2015). A troca iônica é preferencial para o polimento dos produtos obtidos da lixiviação e extração por solventes, devido à baixa concentração das TRs a serem retiradas da solução (Fernández \& García Alonso, 2008, Streat, 1986, Texier et al., 2002).

Em alternativa aos métodos clássicos, a biossorção tem sido descrita na literatura científica como um bioprocesso com potencial para a recuperação das TRs por diferentes espécies microbianas (Andrès et al., 2000, Das, 2010, Das et al., 2014, Muraleedharan et al., 1994, Takahashi et al., 2005, Takahashi et al., 2010, Tsuruta, 2002, 2005, 2006a, 2006b, 2007). biossorção consiste num processo de adsorção que se refere a ligação passiva de íons metálicos por biomassa viva ou morta. Entretanto, estudos revelam que se pode ter uma melhor eficiência no processo biossortivo, quando os micro-organismos são imobilizados em matrizes porosas (Arica et al., 2004, Corrêa et al., 2017, Giese et al., 2016).

A tecnologia de imobilização celular consiste no confinamento físico das células em uma região definida de espaço para uso em processos biotecnológicos de operação contínua ou descontínua possibilitando a reutilização das mesmas (Covizzi et al., 2007, Giese, 2015a, b). A maioria dos processos fermentativos industriais convencionais utiliza células livres em suspensão, porém o uso de microrganismos imobilizados permite um aumento da produtividade devido à elevada concentração de células (Freeman \& Lilly, 1998) e, no caso dos processos de biossorção, um aumento na eficiência da recuperação de elementos metálicos devido ao aumento da presença de grupos funcionais (Michalak et al., 2013).

Tendo em vista a possibilidade da aplicação dos biossorventes na recuperação de TR sem soluções diluídas, este trabalho teve como objetivo determinar a saturação do biossorvente constituído pela biomassa da bactéria Bacillus subtilis imobilizada em matriz de gel de alginato de cálcio e enquadrar os dados de equilíbrio em modelos de isotermas de adsorção dos elementos lantânio (La) e samário (Sm) em regime de batelada.

\section{ASPECTOS TEÓRICOS}

O alginato é um polissacarídeo linear constituído por unidades de ácido manurônicoe ácido gulurônico, unidas por ligações glicosídicas do tipo $\beta$ - $(1 \rightarrow 4)$ e $\alpha-(1 \rightarrow 4)$, respectivamente. Estes polissacarídeos podem ser isolados a partir de algas marrons ou também produzidos por bactérias dos gêneros Pseudomonas e Azotobacter. As propriedades mecânicas das esferas de gel de alginato obtidas dependem basicamente de sua composição monomérica e do grau de polimerização, sendo que a capacidade de formar gel depende da presença de íons divalentes como $\mathrm{Ca}^{2+}$ ou $\mathrm{Mg}^{2+}$ assim como de resíduos de ácido gulurônico (Fraser \& Bickerstaff, 1997).

As esferas de alginato são comumente obtidas através da técnica do gotejamento de solução de alginato de sódio $(2-5 \%, \mathrm{~m} / \mathrm{v})$ contendo células microbianas em solução de cloreto de 
cálcio $\left(\mathrm{CaCl}_{2}\right)$ utilizando-se uma bomba peristáltica, conforme ilustrado na Figura 1. A formação do gel de alginato de cálcio consiste em uma reação denominada gelificação iônica, na qual os íons $\mathrm{Ca}^{2+}$ em solução se ligam aos resíduos de guluronato ou manurato (Giese, 2015b). A alta concentração da matriz polimérica favorece a formação de esferas compactas com superfícies uniformes, as quais apresentam alta resistência mecânica e estabilidade tanto durante o processo fermentativo quanto durante o tempo de estocagem (Culpi et al., 2010,Vos et al., 2009).

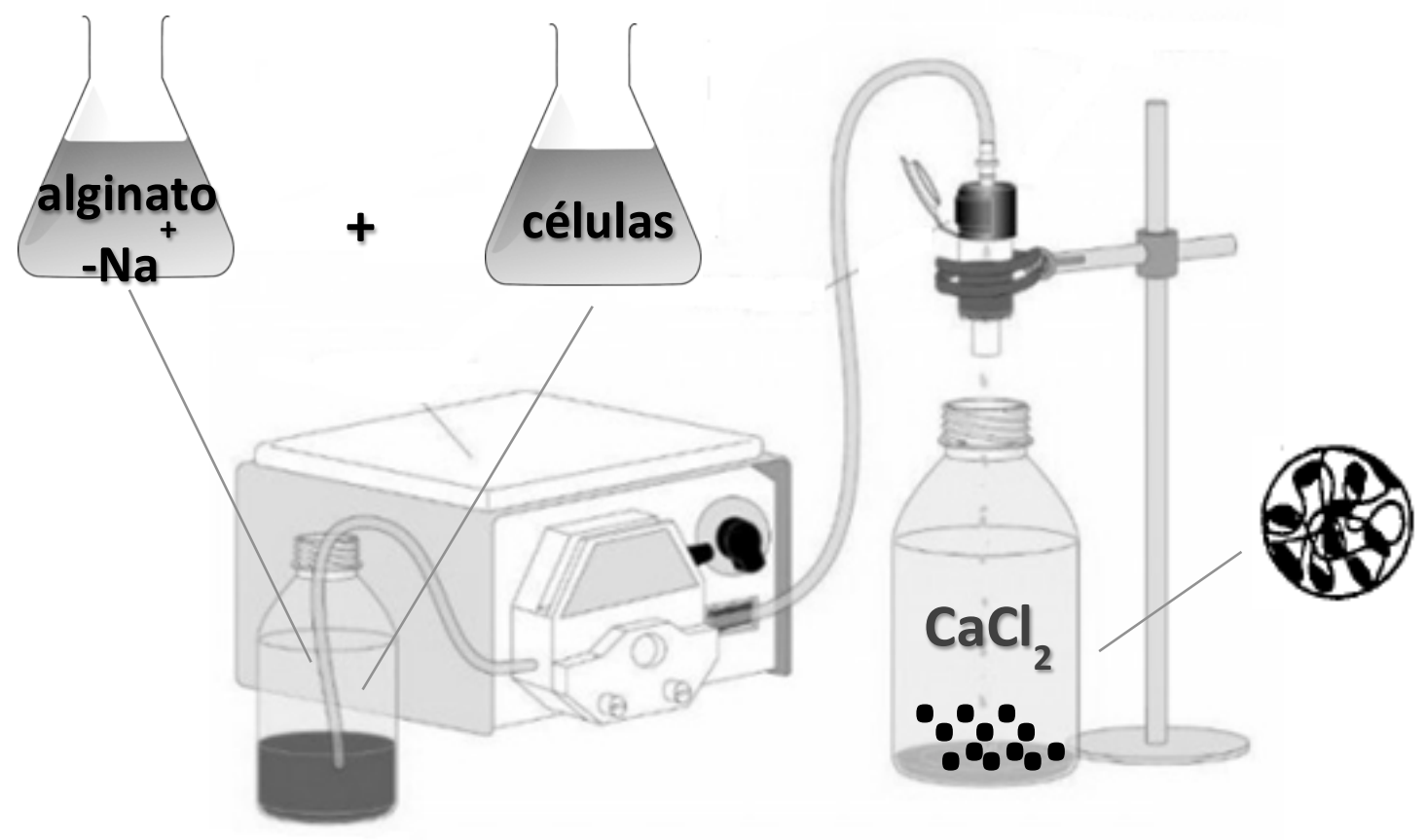

Figura 1: Técnica de gotejamento para imobilização celular em matriz de alginato de cálcio (Giese, $2015 b)$.

Micro-organismos imobilizados em gel de alginato de cálcio vêm sendo utilizados em diversas aplicações biotecnológicas tais como fermentações para a produção de biocombustível, fármacos, vitaminas, entre outros (Giese, 2015a); em processos de biorremediação, biolixiviação e tratamento de drenagem ácida de mina (Giese, 2015b); assim como em processos de biossorção de metais pesados e TRs (Aricaet al., 2004, Corrêa et al., 2017, Michalak et al., 2013).

O gel de alginato de cálcio é considerado um biossorvente eficaz para TRs, tais como lantânio (La) e neodímio (Nd). Wang et al. (2013) sintetizaram um gel de alginato-ácido $\gamma$ poliglutâmico (PGA) que apresentou capacidade máxima de adsorção ( $q_{\text {máx }}$ ) de 1,65 mmol Nd/g e capacidade de reutilização por até oito ciclos consecutivos de absorção-dessorção sem danos ao gel. Em outro estudo, os pesquisadores compararam a $q_{\text {máx }}$ de adsorção de La pelo gel de alginato e pelo gel de alginato-PGA. As isotermas avaliadas resultaram em um valor de $q_{\text {máx }}$ de $0,59 \mathrm{mmol} \mathrm{La} / \mathrm{g}$ para o gel de alginato e de 1,18 $\mathrm{mmol} \mathrm{La} / \mathrm{g}$ para o gel de alginato-PGA. Através de análises de espectroscopia de infravermelho (FT-IR) ficou demonstrado que a adição de PGA tornou as esferas de gel de alginato mais porosas e suscetíveis à adsorção-complexação com La (Xuet al., 2015). 
Por outro lado, o uso de biossorventes formados pela adição de células microbianas à matriz de alginato tem favorecido o aumento da eficiência dos processos de biossorção destes elementos. Os micro-organismos são amplamente estudados quanto ao seu potencial como biossorventes por apresentarem uma área superficial elevada em relação ao seu pequeno tamanho, o que facilita o processo de adsorção dos íons metálicos presentes em solução (Vijayaraghavan \& Yun, 2008).

O estudo cinético da biossorção de La, em concentrações entre 10 e $100 \mathrm{mg} / \mathrm{L}$, pelas biomassas imobilizadas em gel de alginato das microalgas Ankistrodesmus sp. e Golenkinia sp., demonstraram que o biossorvente imobilizado teve o mesmo comportamento das células livres, sendo que o equilíbrio cinético foi alcançado rapidamente nos primeiros minutos em contato. Porém, quando analisados os dados das isotermas no equilíbrio, a qmáx aumentou de $100 \mathrm{mg} \mathrm{La/L}$ (0,72 $\mathrm{mmol} \mathrm{La} / \mathrm{L})$ para $150 \mathrm{mg} \mathrm{La} / \mathrm{L}(1,08 \mathrm{mmol} \mathrm{La} / \mathrm{L})$ para as biomassas livres e imobilizadas de Ankistrodesmus sp., respectivamente; e, de $100 \mathrm{mg} \mathrm{La} / \mathrm{L}$ (0,72 mmol La/L) para $50 \mathrm{mg} \mathrm{La/L} \mathrm{(0,36}$ $\mathrm{mmol} \mathrm{La} / \mathrm{L}$ )para as biomassaslivres e imobilizadas de Golenkinia sp., respectivamente (Corrêa, et al., 2017).

Dentre as cepas bacterianas estudadas como biossorventes de TRs destacam-se as pertencentes aos gêneros Bacillus (Takahashi et al., 2005, Tsuruta, 2007), Streptomyces (Tsuruta, 2006a), Pseudomonas (Andrès et al., 2000, Texier et al., 2002) e Myxococcus (Merroun et al., 2003).

A parede celular da bactéria $B$. subtilis apresenta um sítio de ligação específico para TRs, o qual apresenta menor afinidade para TRs leves e maior afinidade para TRs pesadas, especialmente quando o processo de biossorção é conduzido na faixa de $\mathrm{pH}$ entre 2,5 e 4,5 (Martinez et al., 2014). Esta preferência na biossorção ocorre devido às TRs se ligarem aos sítios ativos da $B$. subtilis através da formação de complexos com grupos fosfato por ligações do tipo fosfoéster, sendo que as ligações com TRs pesadas apresentam um número de coordenação maior com o fosfato que as ligações com TRs leves (Takahashi et al., 2010).

Porém, estudos utilizando biossorventes formados pela combinação de biomassa bacteriana e gel de alginato para aplicação na biossorção de TRs são ainda escassos, sendo necessária a investigação das condições ideais para que este tipo de biossorvente possa ser utilizado para esta finalidade.

\section{MATERIAIS E MÉTODOS}

A partir de placas de Petri pré-existentes contendo a biomassa de $B$. subtilis, uma alçada desta colônia foi transferida para frascos Erlenmeyer de $500 \mathrm{~mL}$ contendo $200 \mathrm{~mL}$ de meio de cultivo (extrato de levedura, $5 \mathrm{~g} / \mathrm{L}$; triptona de soja (TSB), $30 \mathrm{~g} / \mathrm{L}$ ), os quais foram mantidos sob agitação constante a $150 \mathrm{rpm}$ durante $72 \mathrm{~h}$ à $30^{\circ} \mathrm{C}$, para o crescimento das bactérias. Após este período, o cultivo foi interrompido e distribuído em tubos Falcon de $50 \mathrm{~mL}$ para centrifugação a 4000 rpm por 15 min em temperatura ambiente.

A biomassa sedimentada recebeu pré-tratamento com solução de $\mathrm{NaCl} 1 \mathrm{M}$ durante $1 \mathrm{~h}$. A etapa de imobilização celular foi realizada a partir da mistura das células de $B$. subtilis a $120 \mathrm{~mL}$ de solução de alginato de sódio $2 \% \mathrm{~m} / \mathrm{v}$. Com auxílio de uma bomba peristáltica, foram gotejados 
$10 \mathrm{~mL}$ de solução de alginato de sódio $+B$. subtilis em um frasco de Erlenmeyer de $125 \mathrm{~mL}$ contendo $15 \mathrm{~mL}$ de solução $\mathrm{CaCl}_{2} 1 \mathrm{M}$.

Os experimentos de biossorção em batelada foram realizados a partir de soluções sintéticas de cloretos de La e Sm, com sistemas mono-elementares (La ou Sm, separadamente) e bi-elementares (La+Sm). Nos ensaios de biossorção, para cada concentração inicial das espécies estudadas, foram realizados testes em duplicata. Cada Erlenmeyer contendo cerca de 1,10 g de biossorvente $B$. subtilis-alginato recebeu $20 \mathrm{~mL}$ de solução de TRs. Em seguida os Erlenmeyers foram submetidos à agitação constante por $1 \mathrm{~h}$ a $100 \mathrm{rpm} \mathrm{e} 30^{\circ} \mathrm{C}$. Para a construção das isotermas de adsorção, as seguintes concentrações de TRs foram avaliadas: 15, 30, 50, 75 e 100 $\mathrm{mg} / \mathrm{L}$. A determinação da concentração final de La e Smem solução foi realizada utilizando espectrometria de emissão óptica por plasma acoplado indutivamente (ICP-OES, marca Horiba, modelo ULTIMA 2).

O processo de biossorção foi expresso pela capacidade de adsorção(q) do biossorvente $B$. subtilis-alginato em miligramas de TRs adsorvidos por grama de massa seca do biossorvente (mg TR/g) e pela eficiência de remoção (\%) de TRs, as quais foram calculadas através de Equações (1) e (2), respectivamente (Kratochvil \& Volesky, 1998).

$q=\left(\frac{C_{i}-C_{e}}{m}\right) \cdot V$

$\%=\left(\frac{C_{i}-C_{e}}{C_{i}}\right) \cdot 100$

em que, $C_{i}$ é a concentração inicial de TRs em solução $(\mathrm{mg} / \mathrm{L}) ; C_{e}$ é a concentração em equilíbriode TRs em solução ( $\mathrm{mg} / \mathrm{L}) ; \mathrm{m}$ é a massa do biossorvente na mistura reacional $(\mathrm{g})$; $V$ é o volume da mistura reacional (L).

\section{RESULTADOS E DISCUSSÃO}

A capacidade de adsorção e a força com a qual as TRs se ligam aos materiais biossorventes podem ser avaliadas quantitativamente através de isotermas. As isotermas de adsorçãofornecem informações importantes sobre o mecanismo de biossorção, através de parâmetros de ajustes obtidos de modelos matemáticos que os representam tais como Langmuir e Freundlich (Das, 2010). A eficiência da biossorção dependerá principalmente de parâmetros como concentração dos íons, concentração de biomassa biossorvente, $\mathrm{pH}$ da solução e temperatura.

A avaliação quantitativa da biossorção de La e Sm pelo biossorvente $B$. subtilis-alginato foi realizada através de experimentos em diferentes concentrações iniciais de La e Sm como descrito nas Tabelas 1 e 2. Pode-se observar que a eficiência de remoçãoem \% de La e Sm não apresentou alteração significativa $(p<0,05)$ com o aumento das concentrações iniciais destas TRs em solução. 
Tabela 1: Capacidades de biossorção e \% de diferentes concentrações iniciais $\left(C_{\text {inicial }}\right)$ de La para o biossorvente $B$. subtilis-alginato.

\begin{tabular}{l|l|l}
\hline $\begin{array}{l}C_{\text {inicial de La }} \\
(\mathrm{mg} / \mathrm{L})\end{array}$ & $\begin{array}{l}\mathrm{q} \\
(\mathrm{mg} / \mathrm{g})\end{array}$ & $\begin{array}{l}\text { Biossorção } \\
(\%)\end{array}$ \\
\hline 22,3 & $19,12 \pm 0,19$ & $94,39 \pm 0,95$ \\
37,2 & $31,38 \pm 0,45$ & $92,88 \pm 1,33$ \\
51,8 & $43,73 \pm 0,19$ & $92,95 \pm 0,41$ \\
93,2 & $77,52 \pm 0,45$ & $91,58 \pm 0,53$ \\
100 & $81,10 \pm 0,64$ & $89,30 \pm 0,71$ \\
\hline
\end{tabular}

Tabela 2: Capacidades de biossorção e \% de diferentes concentrações iniciais $\left(C_{\text {inicial }}\right)$ de Sm para o biossorvente $B$. subtilis-alginato.

\begin{tabular}{l|l|l}
\hline $\begin{array}{l}\mathrm{C}_{\text {inicial }} \text { de Sm } \\
(\mathrm{mg} / \mathrm{L})\end{array}$ & $\begin{array}{l}\mathrm{q} \\
(\mathrm{mg} / \mathrm{g})\end{array}$ & $\begin{array}{l}\text { Biossorção } \\
(\%)\end{array}$ \\
\hline 14,7 & $12,67 \pm 0,03$ & $94,90 \pm 0,19$ \\
24 & $20,71 \pm 0,00$ & $95,00 \pm 0,00$ \\
48,7 & $41,91 \pm 1,09$ & $94,76 \pm 2,47$ \\
68,7 & $57,58 \pm 0,26$ & $92,29 \pm 0,41$ \\
100 & $83,51 \pm 0,83$ & $91,95 \pm 0,92$ \\
\hline
\end{tabular}

Porém, a capacidade de adsorção (q) para estes elementos aumentou em função do aumento da concentração de TRs em torno de $81,10 \mathrm{mg} \mathrm{La} / \mathrm{g}(0,58 \mathrm{mmol} \mathrm{La} / \mathrm{g})$ e $83,51 \mathrm{mg} \mathrm{Sm} / \mathrm{g}$ $(0,56 \mathrm{mmol} \mathrm{Sm} / \mathrm{g})$. Estes resultados indicam que possivelmente sítios energeticamente menos favoráveis se envolvem no processo de biossorção quando a concentração de TR em solução aumenta. A captação de TR poderia então ser creditada a diferentes mecanismos de troca-iônica ou de adsorção; e tanto o gel de alginato de cálcio utilizado como suporte ou a biomassa da bactéria $B$. subtilis podem estar contribuindo na performance de biossorção das TRs avaliados. Acredita-se que uma investigação mais aprofundada deve ser realizada para esclarecimentos sobre os mecanismos físicos, químicos ou biológicos envolvidos.

Os estudos de equilíbrio da biossorção de La e Sm pelo biossorvente $B$. subtilis-alginato foram processados utilizando modelos de isotermas de Langmuir (Langmuir, 1918) e Freundlich (Freundlich, 1906). A isoterma de Langmuir é utilizada para uma sorção em monocamada na superfície da partícula, a qual contém um determinado número de sítios livres para realizar a biossorção, e pode ser expressa pela Equação (3).

$\frac{\mathrm{Ce}}{\mathrm{Qe}}=\frac{1}{\mathrm{Q}_{\mathrm{m}} \mathrm{K}_{\mathrm{L}}}+\frac{1}{\mathrm{~K}_{\mathrm{L}}} \mathrm{Ce}$

onde Ce é a concentração da TR em solução no equilíbrio ( $\mathrm{mg} / \mathrm{L})$; Qe é quantidade de TR adsorvida por grama do biossorvente $(\mathrm{mg} / \mathrm{g}) ; Q_{m}$ é uma constante relacionada com a energia de adsorção (L/mg) e $\mathrm{K}_{\mathrm{L}}$ é a constante de Langmuir da capacidade de adsorção teórica na monocamada (L/g).

A isoterma de Freundlich está baseada na sorção de superfícies heterogêneas, e é dada pela Equação (4). 
$\log (w / z)=\log K+(1 / n) \log (C e)$

onde w é a massa da TR em solução (mg); z é a massa do biossorvente (g); Ce é a concentração da TR em solução no equilíbrio e $\mathrm{K}$ e $\mathrm{n}$ são constantes de Freundlich relacionadas a capacidade de adsorção e a intensidade de adsorção respectivamente.

A capacidade de adsorção das espécies iônicas de La e Sm pelo biossorvente $B$. subtilisalginatoem sistemas mono-elementares, ou seja, sistemas contendo as TRs avaliadas separadamente, estão apresentadas na Figura 2.

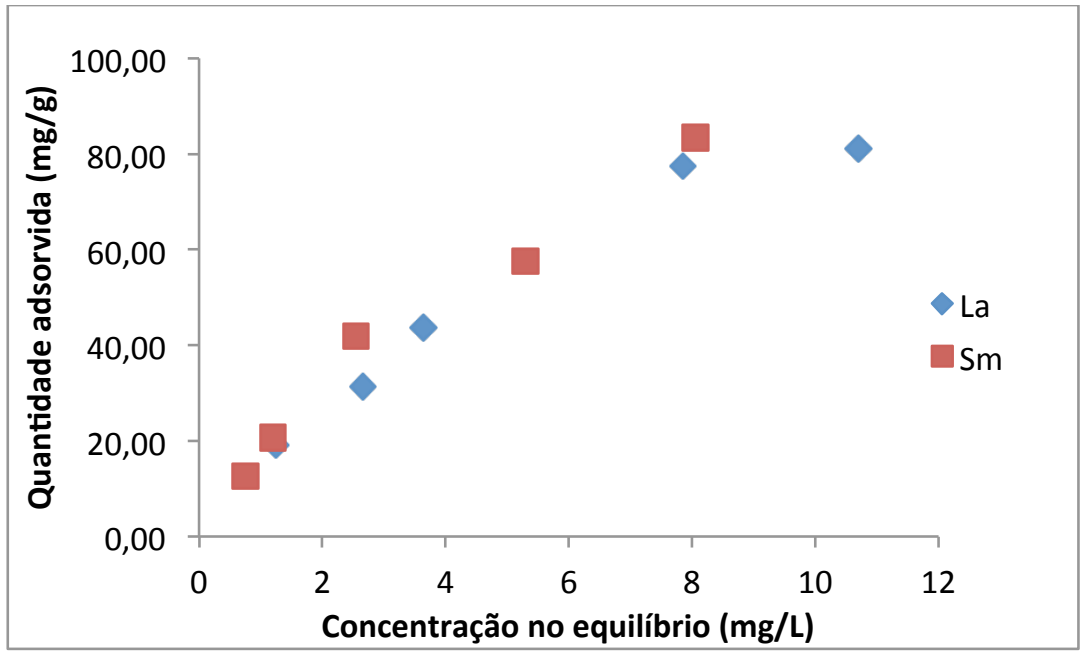

Figura 2: Capacidade de adsorção das espécies La e Sm pelo biossorvente $B$. subtilis-alginato em sistemas monoelementares.

De acordo com os dados apresentados na Figura 2, o biossorvente $B$. subtilis-alginato aparentou exibir uma leve preferência pela sorção de TRs médias em relação às TRs leves (Sm>La). Esta preferência também foi observada na Figura 3, a qual apresenta asisotermas de adsorção das espécies iônicas de La e Sm em sistemas bi-elementares, ou seja, sistemas contendo as TRs avaliadas conjuntamente.

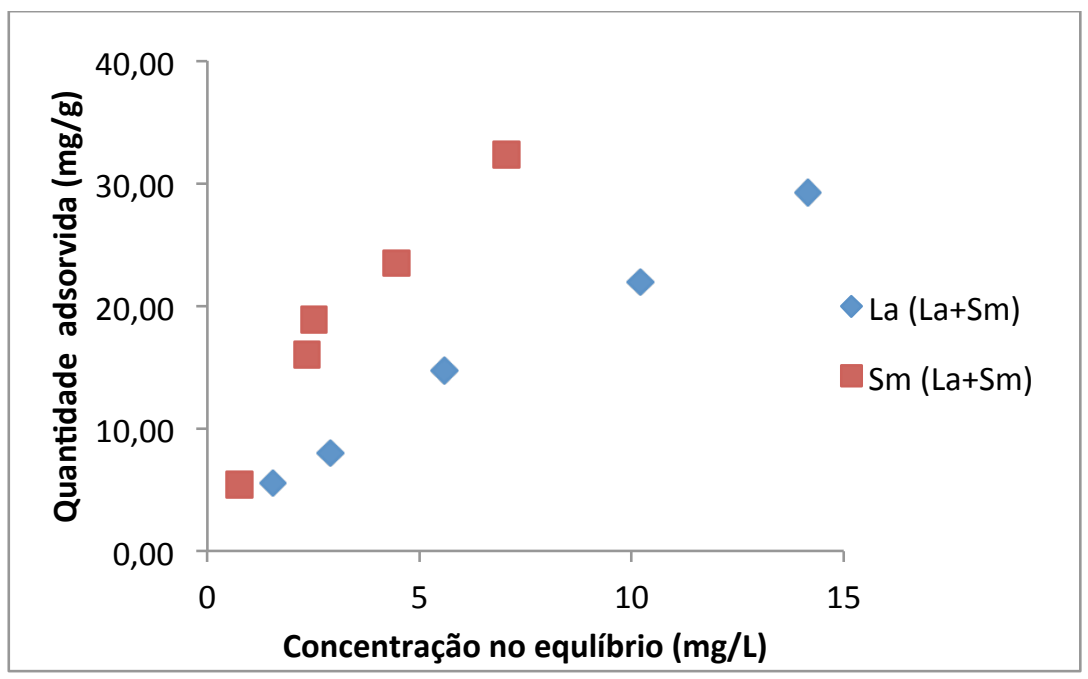

Figura 3: Capacidade de adsorção das espécies La e Sm pelo biossorvente B. subtilis-alginato em sistemas bielementares. 
Porém, a afinidade do material biossorvente pelas TRs deve ser avaliada pelo ajuste dos dados experimentais de biossorção aos modelos de isotermas previamente descritas. Os parâmetros das isotermas de Langmuir e de Freundlich, calculados para todas as espécies testadas nos sistemas mono- ( $\mathrm{La}$ ou $\mathrm{Sm}$ ) e bi-elementares ( $\mathrm{La}+\mathrm{Sm}$ ) estão apresentados na Tabela 3.

Tabela 3: Parâmetros de Langmuir e Freundlich para a biossorção de La e Sm pelo biossorvente B. subtilis-alginato.

\begin{tabular}{l|l|l|l|l|l}
\hline \multirow{2}{*}{ Isotermas } & \multirow{2}{*}{ Adsorvato } & \multicolumn{2}{l|}{ Sistemas mono-elementares } & \multicolumn{2}{l}{ Sistemas bi-elementares } \\
\cline { 3 - 6 } & & $\mathrm{La}$ & $\mathrm{Sm}$ & $\mathrm{La}(\mathrm{La}+\mathrm{Sm})$ & $\mathrm{Sm}(\mathrm{La}+\mathrm{Sm})$ \\
\hline Langmuir & $\mathrm{Q}_{\mathrm{m}}(\mathrm{L} / \mathrm{mg})$ & 0,10 & 0,12 & 0,05 & 0,12 \\
& $\mathrm{~K}_{\mathrm{L}}(\mathrm{L} / \mathrm{g})$ & 161,3 & 166,7 & 66,2 & 69,4 \\
& $\mathrm{R}^{2}$ & 0,94 & 0,91 & 0,89 & 0,88 \\
& $\mathrm{R}_{\mathrm{L}}$ & 0,06 & 0,05 & 0,22 & $1,04 \mathrm{E}-01$ \\
\hline Freundlich & $\mathrm{K}$ & 1,06 & 1,10 & 1,22 & 1,16 \\
& $\mathrm{n}$ & 0,97 & 0,98 & 0,93 & 0,97 \\
& $1 / \mathrm{n}$ & 1,03 & 1,02 & 1,08 & 1,03 \\
& $\mathrm{R}^{2}$ & 0,99 & 0,99 & 0,99 & 0,99 \\
\hline
\end{tabular}

O parâmetro $\mathrm{K}_{\mathrm{L}}$ nos ensaios em sistemas mono-elementaresapresentou valores expressivos (161,3 L/g para La e 166,7 L/g para Sm), representando grande afinidade do biossorvente pelas TRs quando avaliadas separadamente. Nos ensaios bi-elementares, os valores do parâmetro $K_{\mathrm{L}}$ diminuíram quase 3 vezes (66,2 L/g para La e 69,4 L/g para Sm).

Os valores obtidos para $\mathrm{K}_{\mathrm{L}}$ demonstraram que o $\mathrm{Sm}$ é removido da solução e adsorvido mais rapidamente que o La. Entretanto, os valores calculados para este parâmetro são muito similares de maneira que os mesmos não são suficientes para inferir tal informação. No caso da biossorção de La e Nd pela macroalga Sargassum sp., os valores de $K_{L}$ obtidos foram maiores para La $(505,11 \mathrm{~L} / \mathrm{g})$ em comparação com $\mathrm{Nd}(481,80 \mathrm{~L} / \mathrm{g})$, demonstrando a preferência da alga marrom pela adsorção de TRs leves (Oliveira et al., 2012).

As regressões lineares apresentaram boas aproximações, conforme pode ser observado em seus coeficientes de correlação $\left(R^{2}\right)$ em ambas as isotermas para os dois sistemas avaliados. Pode-se observar que o modelo de isoterma de Langmuir se adaptou adequadamente aos pontos experimentais quando as espécies iônicas La e Sm foram tratadas isoladamente, pois apresentaram valores de $R^{2}$ entre 0,94 e 0,91, respectivamente. No caso da biossorção destas TRs em sistemas bi-elementares, a competição de La e Sm pelos sítios ativos de adsorção presentes no biossorvente $B$. subtilis-alginato, em todos os contatos, pode ter feito com que os ajustes para esse modelo testado apresentassem valores menores em termos de $R^{2}(0,89$ para La e 0,88 para $\mathrm{Sm})$.

Para o modelo de isoterma de Freundlich, os valores de $\mathrm{R}^{2}$ para La e $\mathrm{Sm}$ em ambos os sistemas mono- e bi-elementares foram iguais à 0,99, apresentando melhor ajuste dos dados experimentais. Os valores de $n$ encontrados, relativo à distribuição das espécies iônicas de La e Sm ligadas aos sítios ativos do biossorvente avaliado, foram bem próximos à 1, porém um pouco ainda menores. Uma adsorção favorável apresenta valores para a constante $n$ entre 1 e 10, sendo 
que valores mais baixos indicam uma menor interação entre o material biossorvente e o soluto avaliado (Loukidou et al., 2004).O processo de biossorção em questão foi mais favorável de acordo com a isoterma de Langmuir, uma vez que todos os valores de $R_{L}$ se apresentaram dentro da faixa de valores $0<R_{L}<1$, onde a adsorção é considerada favorável (Langmuir, 1918).

Os valores apresentados para os parâmetros $K_{L}$ e $R^{2}$, portanto, indicam que o biossorvente avaliado apresenta afinidade muito semelhante para La e Sm. A diferença entre os valores dos parâmetros para as TRs, discretamente maiores para $\mathrm{Sm}$, não foi significativa ( $p$ $<0,05)$; desta maneira os mesmos não foram suficientes para descrever a seletividade de TRs leves e médias pelo biossorvente avaliado.

\section{CONCLUSÕES}

O estudo demonstra o potencial de aplicação da biomassa da bactéria $B$. subtilis suportada em alginato de cálcio como um biossorvente para La e Sm em soluções aquosas diluídas. A aplicação dos dados obtidos aos modelos de adsorção de Langmuir e Freundlich mostrou que as isotermas de adsorção obtidas para La e Sm foram satisfatórias para ambos os modelos, sendo que este processo de biossorção apresentou melhor ajuste dos dados experimentais de acordo com o modelo de Freundlich e demonstrou ser favorável pelo modelo de Langmuir. Isto sugere a ocorrência da biossorção em monocamada assim como condições heterogêneas na superfície, onde ambas condições podem co-existir sob as condições experimentais testadas. Maiores estudos serão necessários para descrever a afinidade do biossorvente $B$. subtilis-alginato pelas TRs estudadas.

\section{AGRADECIMENTOS}

À FAPERJ e CNPq pelo apoio à realização do projeto. N Coimbra agradece ao programa $\mathrm{PCl} / \mathrm{CNPq} / \mathrm{CETEM}$ pela bolsa concedida.

\section{REFERÊNCIAS}

Andrès, Y., Thouand, G., Boualam, M., \& Mergeay, M. (2000). Factors influencing the biosorption of gadolinium by micro-organisms and its mobilisation from sand. Applied Microbiology and Biotechnology, 54, 262-267.

Arica, Y., Bayramoglu, G., Yilmaz, M., Bekta, S., \& Genç, Ö. (2004).Biosorption of $\mathrm{Hg}^{2+}, \mathrm{Cd}^{2+}$, and $\mathrm{Zn}^{2+}$ by $\mathrm{Ca}$-alginate and immobilized wood-rotting fungus Funalia trogii. Journal of Hazardous Materials, B109, 191-199.

Corrêa, F. N., Luna, A. S., \& Costa, A. C. A. (2017). Kinetics and equilibrium of lanthanum biosorption by free and immobilized microalgal cells. Adsorption Science \& Technology, 35, 137-152.

Covizzi, L. G., Giese, E. C., Gomes, E., Dekker, R. F. H., \& Silva, R. (2007). Imobilização de células microbianas e suas aplicações biotecnológicas. Semina: Ciências Exatas e Tecnológicas,28, 143-160. 
Culpi, T. A., Pasqualim, P, Fin, M. T., Sasso, D. G. B., Kaminski, G. A. T., Fujiwara, G. M., Nunes, P. M. P., Rodrigues, B. H., Dias, J. F. G., \& Zanin, S. M. W. (2010). Importância de parâmetros de controle na elaboração de micropartículas de $\mathrm{Ca}^{2+}$-alginato. Visão Acadêmica, 11, 38-44.

Das, N. (2010). Recovery of precious metals through biosorption - a review. Hydrometallurgy, 103, 180-189.

Das, D., Varshini, C. J. S..\& Das, N. (2014). Recovery of lanthanum (III) from aqueous solution using biosorbents of plant and animal origin: Batch and column studies. Minerals Engineering, 69, 40-56.

Fernández, R. G., \& García Alonso, J. I. (2008). Separation of rare earth elements by anionexchange chromatography using ethylenediaminetetraacetic acid as mobile phase .Journal of Chromatography A, 1180, 59-65.

Fraser J.E., \& Bickerstaff G.F. (1997) Entrapment in calcium alginate. In: Bickerstaff, G.F. (eds) Immobilization of Enzymes and Cells. Methods in Biotechnology, vol 1. Humana Press.

Freeman, A., \& Lilly, M. D. (1998). Effect of processing parameters on the feasibility and operational stability of immobilized viable microbial cells. Enzyme and Microbial Technology, 23, 335-345.

Freundlich H. (1906). Over the adsorption in solution. The Journal of Physical Chemistry, 57, 384410.

Giese, E. C. (2015a). Biocatalisadores imobilizados: Prospecção de inovações tecnológicas na última década. Revista GEINTEC: gestão, inovação e tecnologias, 5, 2296-2307.

Giese, E. C. (2015b). Potencial biotecnológico do uso de micro-organismos imobilizados em gel de alginato de cálcio. Série Tecnologia Ambiental, 81. CETEM/MCTIC, 49p.

Giese, E. C., Magalhães, D. P., \& Egler, S. G. (2016). Biossorção de elementos de terras-raras. Série Tecnologia Mineral, 90. CETEM/MCTIC, 75p.

Giese, E. C. (2017). Tendências européias para o uso dos recursos de terras-raras. Série Estudos e Documentos, 93. CETEM/MCTIC, 30p.

Kratochvil, D. E., \& Volesky, B (1998). Advances in the biosorption of heavy metals. Reviews Tibtech, 16, 291-300.

Langmuir, I. (1918). Adsorption of gases on plane surfaces of glass, mica and platinum. Journal of the American Chemical Society, 40, 1361-1403.

Loukidou, M. X., Zouboulis, A. I., Karapantsios, T. D., \& Matis, K. A. (2004). Equilibrium and kinetic modeling of chromium (VI) biosorption by Aeromonas caviae. Colloids and Surfaces, 242, 93104.

Martinez, R. E., Pourret, O., \& Takahashi, Y. (2014). Modeling of rare earth element sorption to the Gram-positive Bacillus subtilis bacteria surface. Journal of Colloid and Interface Science, 413, 106-111.

Merroun, M. L., Ben Chekroun, K., Arias, J. M., \& Gonzalez-Muñoz, M. T. (2003). Lanthanum fixation by Myxococcus xanthus: cellular location and extracellular polysaccharide observation. Chemosphere, 52, 113-120.

Michalak, I., Choinacka, K., \& Witek-Krowiak, A. (2013). State of the art for the biosorption process - a review. Applied Biochemistry and Biotechnology, 170, 1389-1416.

Muraleedharan, T. R., Philip, L., lyengar, L., \& Venkobachar, C. (1994). Application studies of biosorption for monazite processing industry effluents. Bioresource Technology, 49, 179-186. 
Oliveira, R. C., Guibal, E.,\& Garcia Jr., O. (2012). Biosorption and desorption of lanthanum(III) and neodymium (III) in fixed-bed columns with Sargassum sp.: Perspectives for separation of rare earth metals. Biotechnology Letters, 28, 715-722.

Silva Júnior, A. F., \& Campos, M. F. (2016). Relevância das terras raras para o setor energético. HOLOS, 1, 350-364.

Streat, M. (1986) Applications of Ion Exchange in Hydrometallurgy. In: Rodrigues, A.E. (eds) Ion Exchange: Science and Technology. NATO ASI Series (E: Applied Sciences), vol 107. Springer, Dordrecht.

Takahashi, Y., Chatellier, T. X., Hattori, K. H., Kato, K.,\& Fortin, D. (2005). Adsorption of rare earth elements onto bacterial cell walls and its implication for REE sorption onto natural microbial mats.Chemical Geology, 219, 53-67.

Takahashi, Y., Yamamoto, M., Yamamoto, Y., \& Tanaka, K. (2010). EXAFS study on the cause of enrichment of heavy REEs on bacterial cell surfaces. Geochimica et Cosmochimica Acta, 74, 5443-5462.

Texier, A. C., Andrès, Y., Faur-Brasquet, C., \& Le Cloireç, P. (2002). Fixed-bed study for lanthanide (La, Eu, Yb) ions removal from aqueous solutions by immobilized Pseudonomas aeruginosa: experimental data and modelization. Chemosphere, 47, 333-342.

Tsuruta, T. (2002). Removal and recovery of uranyl ion using various microorganisms. Journal of Bioscience and Bioengineering, 94, 23-28.

Tsuruta, T. (2005). Separation of rare earth elements by microorganisms. Journal of Nuclear and Radiochemical Sciences, 6, 81-84.

Tsuruta, T. (2006a). Bioaccumulation of uranium and thorium from the solution containing both elements using various microorganisms. Journal of Alloys and Compounds, 408-412, 13121315.

Tsuruta, T. (2006b). Selective accumulation of light or heavy rare earth elements using grampositive bacteria.Colloids and Surfaces B: Biointerfaces, 52, 117-122.

Tsuruta, T. (2007). Accumulation of rare earth elements in various microorganisms. Journal of Rare Earths, 25, 526-532.

Vera, Y.M. (2015). Separação de terras raras a partir da extração por solvente: revisão sobre o uso dos extratantes ácidos organofosforados. Série Tecnologia Mineral, 94. CETEM/MCTIC, $59 \mathrm{p}$.

Vijayaraghavan, K.,\&Yun, Y-S. (2008). Bacterial biosorbents and biosorption. Biotechnology Advances, 26, 266-291.

Vos, P., Bucko, M., Gemeiner, P., Navrátil, M., Stivel, J., Faas, M., Strand, B. L., Skjak-Braek, G., Morch, Y. A., Vikartovská, A., Lacik, I., Kolláriková, G., Orive, G., Poncelet, D., Pedraz, J. L., \& Ansorge-Schumacher, M. B. (2009). Multiscale requirements for bio-encapsulation in medicine and biotechnology. Biomaterials, 30, 2559-2570.

Wang, F., Zhao, J., Wei, X., Huo, F., Li, W., Hu, Q.,\& Liu, H. (2014), Adsorption of rare earths (III) by calcium alginate-poly glutamic acid hybrid gels. Journal of Chemical Technology and Biotechnology, 89, 969-977.

Xu, S., Wang, Z., Gao, Y., Zhang, S.,\& Wu, K. (2015). Adsorption of rare earths (III) using an efficient sodium alginate hydrogel cross-linked with poly- $\gamma$-glutamate. PLOS One, 10, e0124826. doi:10.1371\%2Fjournal.pone.0124826 